\title{
making sense of medical education
}

\section{Video and qualitative research: analysing medical practice and interaction}

\author{
Christian Heath, Paul Luff \& Marcus Sanchez Svensson
}

CONTEXT Video has long been recognised as providing an important resource within medical education, particularly, perhaps, for training in primary health care. As a resource for research, and more specifically within qualitative social science studies of medical practice, video has proved less pervasive, despite its obvious advantages.

METHODS In this paper, we sketch an approach to using video to inform the analysis of medical practice and the ways in which health care is accomplished through social interaction and collaboration. Drawing on our own research, we discuss two brief examples: the first involves the use of computing technology in primary health care and the second concerns informal instruction during surgery. The examples illustrate the multimodal character of medical work, how activities are accomplished through the interplay of talk, the visual and the use of material artefacts. They also illustrate the ways in which video provides access to the complex forms of social interaction and collaboration that underpin health care.

DISCUSSION We reflect upon the research opportunities afforded by video and the ways in which video-based studies of interaction can contribute to the practice and practicalities of medicine.

KEYWORDS *video recording; *clinical medicine; surgery, computer-assisted; decision making, computer-assisted; primary health care; education, medical.

Medical Education: 2007; 41: 109-116

doi:10.1111/j.1365-2929.2006.02641.x

King's College London, London, UK

Correspondence: Christian Heath, Work, Interaction and Technology, Department of Management, King's College London, Franklin-Wilkins Building, 150 Stamford Street, London SE1 9NH, UK.

Tel: 0044207848 4142; Fax: 0044207848 4254;

E-mail: christian.heath@kcl.ac.uk

\section{INTRODUCTION}

Video has long been recognised as providing an important resource for training and education in medicine. Indeed, within a few years of the introduction of cheap and reliable video technology, a number of medical schools began to use video to help train undergraduate and postgraduate students in interpersonal skills. As far as we are aware, the General Practice Department at the University of Manchester, led by Patrick Byrne, ${ }^{1}$ pioneered the systematic use of video as part of its postgraduate trainee programme in the early 1970s. These innovations became widespread in primary health care over the following decade and foreshadowed the more general introduction of video-based skills training within the medical curriculum. Alongside these developments, there has been growing commitment to using video for social research. Thus, over the last decade or so we have seen a small but growing corpus of video-based research in medicine, concerned with such topics as the communication and diagnosis of mental health problems, variations in clinical skills and practice, and the introduction and use of new technology in the consultation. ${ }^{2-7} \mathrm{We}$ discuss these initiatives and briefly sketch a distinctive approach to video-based research that is naturalistic and qualitative and addresses the multimodal and interactional accomplishment of medical work.

In this paper, we introduce a way of using video to analyse the interactional accomplishment of medical practice and draw out its implications for training and education. We will provide two very brief examples, the first of which is concerned with the use of computers in primary health care, while the second focuses on instruction during surgery. These examples demonstrate the ways in which video augmented by field work can provide access to the fine details of participants' conduct and interaction. This paper is 


\section{Overview}

\section{What is already known on this subject}

There is a growing interest in using video, particularly audio-visual recordings, to undertake naturalistic analysis of talk and interaction in medicine. Despite a growing body of empirical studies, there are very few papers that discuss the practical and methodological issues that arise in analysing the fine-grained actions and activities of practitioners and patients.

\section{What this study adds}

Using examples drawn from primary health care and operating theatres, we delineate a number of key considerations and procedures that researchers may use to analyse medical interaction using video.

\section{Suggestions for further research}

The paper will provide a basis to enable researchers from various disciplines to consider how they might use video to analyse medical practice.

concerned with recommending a particular methodological orientation to the use of video to analyse human conduct, an orientation that we believe allows researchers to grapple with the complex and contingent character of practice and interaction in everyday medical work. Although this paper is primarily concerned with delineating and illustrating one or two aspects of these methodological commitments, we also wish to briefly point to the potential practical and educational implications of placing the details of social interaction at the heart of the analytic agenda.

This paper deals to some extent with data collection and some of the practical and ethical issues that arise in using video for social research. However, it is important to mention that although a broad range of medical settings have been subject to video-based research and training, including, for example, primary health care, paediatrics, psychiatry, surgery and dentistry, each and every setting is subject to practical and moral constraints on data collection that can limit the form and quality of the data available.

\section{BACKGROUND}

Over the last couple of decades or so, we have witnessed the emergence of a growing corpus of naturalistic studies of the talk in medical settings. These studies have used audio and audio-visual recordings of consultations and encounters in health care to examine the fine details of interpersonal communication..$^{8-13}$ They have powerfully demonstrated ways in which everyday medical practice is accomplished through the systematic organisation and contingent character of talk and how seemingly insignificant features of talk's production are critical to the diagnosis and management of illness. They reveal how audio-recordings coupled with a relevant methodological framework can provide insights and observations in medical practice that are unavailable through conventional field work. These studies draw upon ethnomethodology and conversation analysis and the analytic initiatives of Garfinkel ${ }^{14}$ and Sacks. ${ }^{15}$ The visual and material aspects of interaction have received less attention. However, it is increasingly recognised that bodily comportment, visual orientation, gesture and so forth, coupled with the pervasive use of tools and technologies in work and organisation, demand analytic attention and provide ways of enriching our understanding of institutional forms of interaction in areas such as the delivery of health care. In light of this, there is a growing body of videobased field research that draws on ethnomethodology and conversation analysis to address the ways in which organisational activities are accomplished through the interplay of talk, the visual and material, including the use of tools and technologies. This corpus of research has come to be known as 'workplace studies' and includes studies carried out in organisational environments such as control centres, newsrooms and trading rooms, and, increasingly, studies performed in medical settings such as operating theatres, call centres and primary care practices. $^{16-20}$ It is these analytic and empirical developments that we wish to briefly discuss in this paper.

Video-based field studies that draw on ethnomethodology and conversation analysis stand in marked contrast to more traditional ethnographies of medical practice and health care. Although they share a common commitment, like much qualitative research, to prioritising the 'participant's perspective', they address this methodological concern in a distinctive and we believe more rigorous fashion. In general, the studies are driven by three principal analytic commitments. In the first place, the 
contextual or situated character of practical action and interaction is placed at the heart of the analytic agenda. It is recognised that the sense and significance of an activity is embedded within the situation and circumstances in which it is produced; the analysis of social action demands a detailed understanding of the ways in which activities are accomplished with regard to the context and contingencies at hand and, in particular, the real-time contributions of others. Secondly, social action and activities are accomplished in and through social interaction, and interaction provides a methodological resource through which we can examine how participants orient themselves to each other's conduct within the developing course of its contingent accomplishment. To paraphrase Heritage (1984), ${ }^{21}$ actions are both 'context-sensitive and context-renewing'. Thirdly, the analysis of action-in-interaction through repeated scrutiny of video-recordings provides the opportunity to examine and explicate the resources, practices, procedures and reasoning on which the participants themselves rely in accomplishing particular actions and in making sense of the contributions of others. In this sense, the interactional accomplishment of social actions and activities is both a topic of, and a resource in, enquiry. ${ }^{14,15,22}$

Two examples illustrate the ways in which we can begin to examine and reflect upon the social and interactional accomplishment of medical work. Both examples reveal the ways in which patients and practitioners orient to the participation of others in accomplishing particular activities. They also point to ways in which the seemingly fine details of communication in medical work may contribute to education and training. (Symbols used in transcriptions are explained in the Appendix.)

\section{COMPUTERS IN PRIMARY HEALTH CARE}

One of the most significant developments in medical practice over the past decade or so has been the widespread introduction of information technology into the delivery of health care. General practice has been at the forefront of these developments and it is widely recognised that computers have had an important impact on communication within the consultation. The ways in which technology features in the interaction between patient and doctor, however, remain relatively unexplored. Consider the following fragment drawn from a large corpus of recordings that were gathered as part of an Economic and Social Research Council (ESRC) project concerned with the introduction of computers into

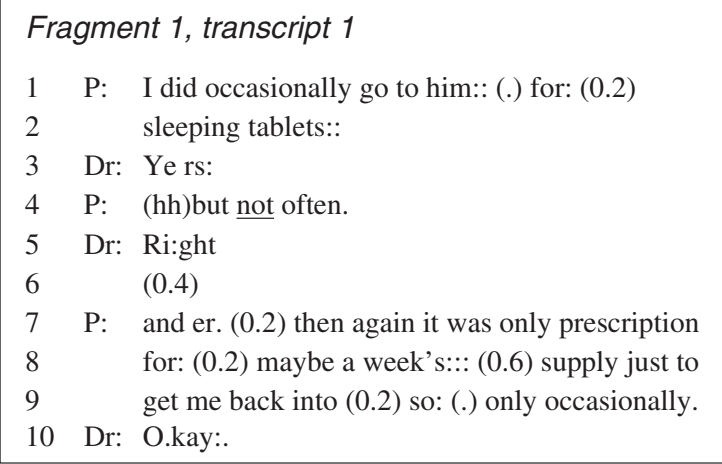

Figure 1 Fragment 1, transcript 1; drawn from a patient-doctor interaction in general practice

primary health care (Fig. 1). We join the action towards the end of the consultation. The doctor asks the patient, who is new to the practice, whether he has any other questions or issues he would like to raise. The patient initially declines but as the doctor begins to enter the prescription details into the computer, the patient mentions that he sleeps quite fitfully and occasionally visited his previous doctor for sleeping tablets. Of particular interest is the patient's utterance, beginning 'and er' (line 7) in which he attempts to minimise the extent and frequency with which he took the tablets.

Whilst the patient's utterance is clearly oriented to the way in which the doctor is acknowledging the 'problem', but not immediately offering the solution, it also appears sensitive to the doctor's participation in the emerging talk, in particular his use of the computer. Throughout much of the utterance the doctor is looking at the screen and occasionally typing. For instance, the patient appears to delay the beginning of the utterance 'and er' (transcript 2) until the doctor completes a series of keystrokes on the computer and raises his right hand from the keyboard (Fig. 2). The patient then pauses once the doctor begins to type, only continuing to talk with 'maybe a week's:::' once the doctor ceases typing. The doctor produces a further keystroke with the word 'week's'. Once again the patient pauses. He then turns towards the doctor. As the patient turns, the doctor raises his right hand from the keyboard and nods. He acknowledges the patient but remains oriented towards the screen. The patient then withholds further talk until the doctor turns towards him, and at that moment he produces 'supply' and continues the utterance.

We can begin to see how the delivery of the patient's reply is sensitive to the conduct of the doctor and in particular the ways in which the doctor enters 

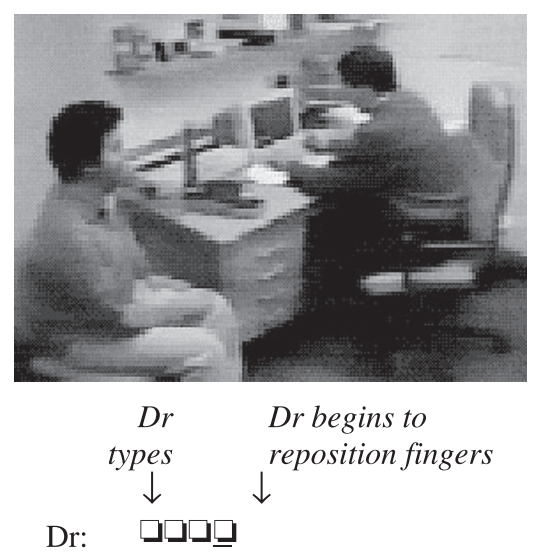

P. Ri:ght -- and er -- then again it was only a prescription for (0.2

$\square \square$
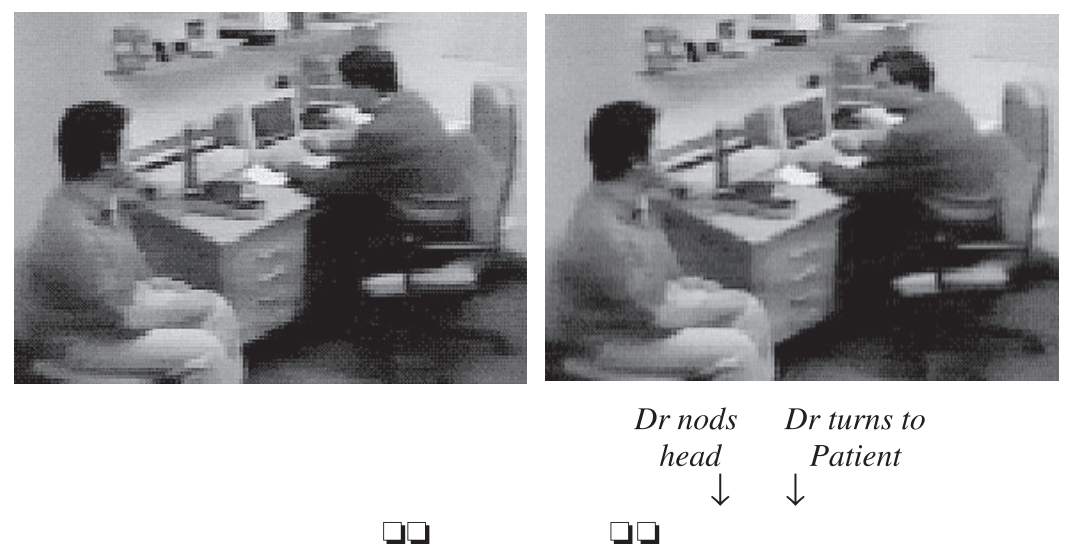

$\square \square$

weeks:::------ supply:

$\uparrow$

Patient turns to Dr

Figure 2 Fragment 1, transcript 2

information into the computer. The patient attempts to produce his reply as the doctor momentarily ceases his use of the computer and successively withholds parts of the utterance until he has secured a reorientation from the doctor. Indeed, both the pauses and the stretches on particular words serve to encourage the doctor to transform the ways in which he is participating, or failing to participate, in the patient's response. ${ }^{23,24}$ For his own part, we find the doctor is sensitive to the patient's orientation to the use of system, at 1 point, for example, he attempts to reconcile the competing demands of the speaker and finish the prescription by simultaneously looking at the screen and nodding his head. The fragment demonstrates how use of the computer can infuse the communication between patient and doctor, and the ways in which doctors and patients may attempt to ameliorate its impact on their talk and engagement. More generally it demonstrates how a turn at talk, in this case a patient's attempt to articulate and justify the possibility of securing sleeping tablets, is an interactional accomplishment emerging in and through a delicate negotiation between patient and doctor.

The fragment also raises some issues of relevance to medical practice and education. For example, we can begin to see how the material aspects of the practitioner's conduct in terms of the use of tools and technologies such as a computer are relevant to the patient's opportunities to present information to the doctor and to discuss his or her complaints and their management. In teaching communication skills, it is increasingly important to enable students and practitioners to see and recognise the implications of the use of artefacts such as computers on patients' abilities and willingness to articulate problems, concerns and difficulties. Secondly, the ways in which patients and doctors orient to and use material resources such as computers are relevant to the design of technologies to support medical work, particularly to the development of systems to enhance medical practice as it is accomplished within everyday health care settings in concert with patients. ${ }^{25}$

\section{OCCASIONED INSTRUCTION}

Instruction and demonstration in medical practice often evolve through complex forms of interaction and depend upon the ways in which practitioners and students fashion each other's participation within the activity at hand. Take, for instance, the surgical operation, an event that is often used to provide trainees and students with instruction and demonstrations of practice. Video can provide a resource for looking at the ways in which 'situated' instruction and learning are accomplished. This requires the surgeon, for example, to interdisperse illustrations and advice to students whilst preserving the integrity of the principal activity - the surgery - carried out in collaboration with other surgeons, nurses and anaesthetists. For the students, the phenomena and procedures may not necessarily be immediately visible or known, so surgeons may take the opportunity to reveal aspects of the operation within the course of its production. These momentary 

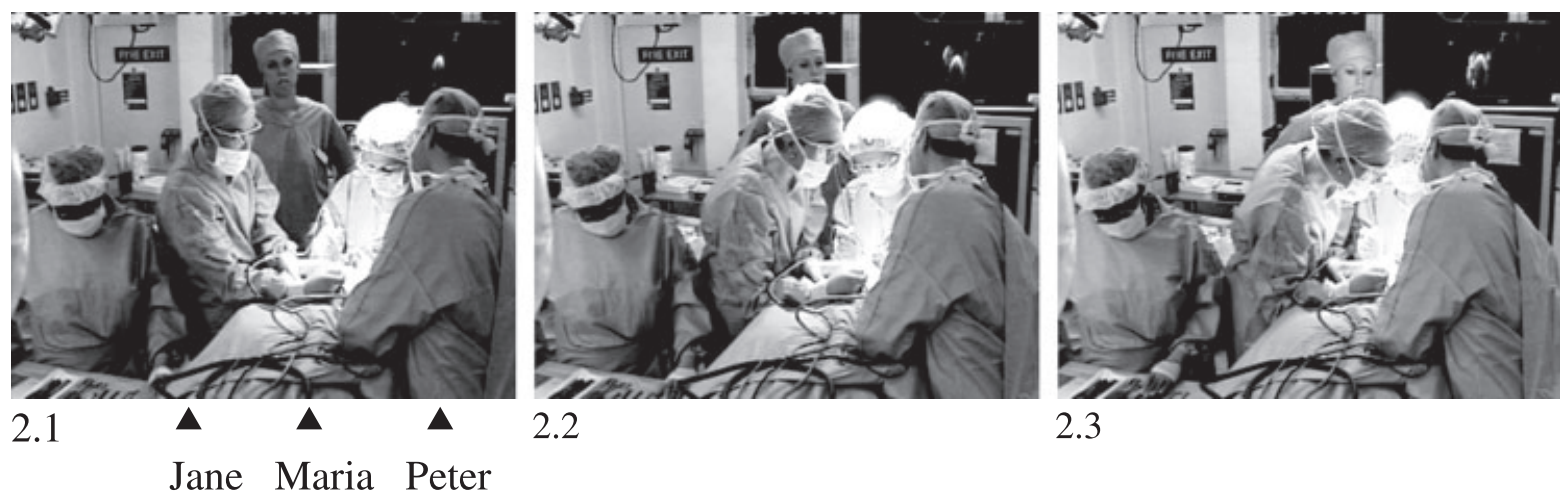

2.2

2.3

Maria: Can you see the line there?

Figure 3 Fragment 2, transcript 1; drawn from an interaction during a surgical procedure

demonstrations demand realigning the participation of the students.

Consider the following fragment (Fig. 3). The surgeon (Maria) is using a drill to gain access to an oesteoma or tumour that has grown out of the bone structure in the cavity of the frontal sinus in the area above the eyebrow (Fig. 3, fragment 2.1). Two surgical trainees (Jane and Peter) have joined the operation as skilled assistants to the surgeon; they provide the necessary support to the surgeon by retracting the skin and placing wet towels on the wound. Two students, outside the direct location of activity, look on. We join the action as the surgeon stops the drill and repositions the suction tip and produces the utterance: 'Can you see the line there' (Fig. 3, fragment 2.2). The question occasions a reorientation by Jane and Peter: they move their heads forward and look toward the surgical field (Fig. 3, fragment 2.3).

The reorientation by the trainees, whilst engendered by the question, does not appear to be sufficient to enable the surgeon to believe that they have discovered the line and location of the oesteoma. A second or so later, she specifies the location of the line: 'the little line here (lying) around it' (line 3 in fragment 2, transcript 2; Fig. 4), and Jane responds with: 'yes' (line 4). A moment later the surgeon attempts to elicit a response that displays, rather than simply claims, discovery of the line: 'do you see it at the bottom there?' (line 5). Jane and Peter once again orient towards the scene in question peering closer to examine the oesteoma. Nevertheless, the surgeon provides further instruction, attempting to enable the trainees to discover the line and location of the object: 'the little V:::' (line 7). In turn the surgeon's utterance elicits: 'mm' (line 8) and a head nod from Jane, but little from Peter (Fig. 5, fragment 2.4). It appears as if the progressive modification of the

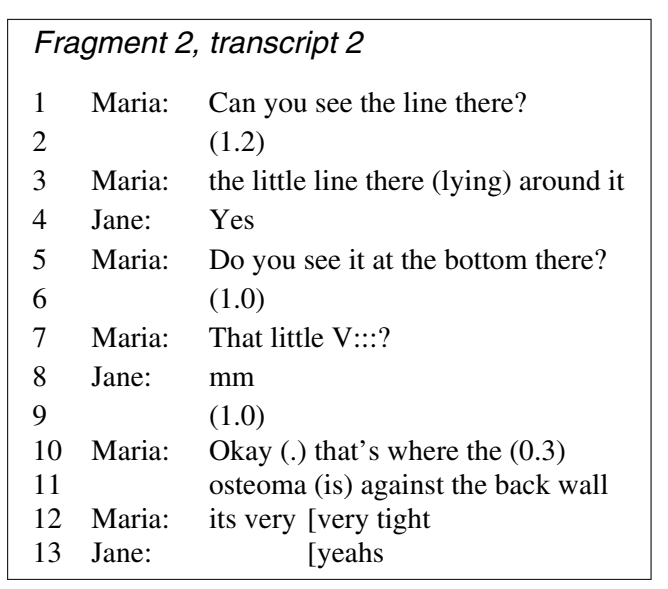

Figure 4 Fragment 2, transcript 2

description is gradually orientated towards the absence of response from Peter. Indeed, as she raises her gaze from the surgical field, the surgeon orients towards Peter (Fig. 5, fragment 2.5) and as she delivers the actual statement: 'that's where the oesteoma is against the back wall' (lines 10-12), she looks at Peter and uses her hand to make a gestural representation of the tumour and its location in the cavity of the frontal sinus.

Revealing the location of the oesteoma, until that moment partially hidden by the surgeon's hands, the drill and blood, enables the trainees to comprehend the ways in which the surgeon is approaching the problem in this case and recognise the difficulties in discovering and removing the growth. It enables the trainees to embed the procedure within the practicalities and constraints of the case, to retrospectively and prospectively make sense of the surgeon's actions. The trainees' discovery and determination of the oesteoma is accomplished through the surgeon's progressive 


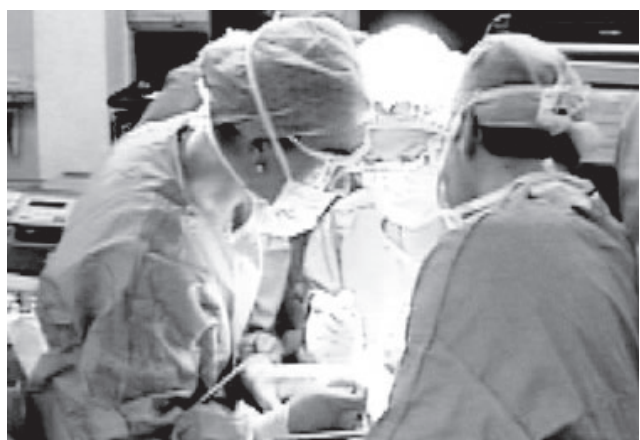

2.4

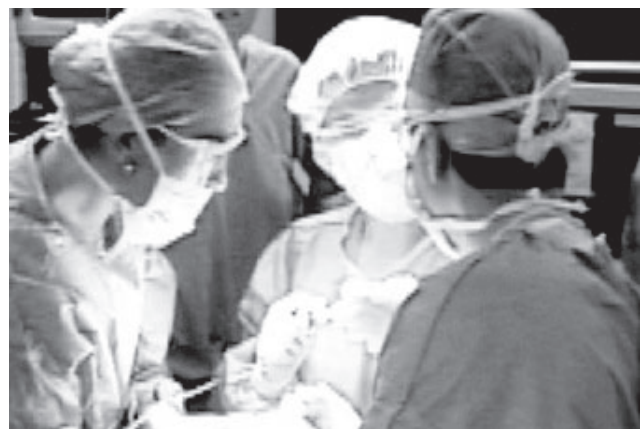

2.5

Figure 5 Fragment 2, transcript 1; continues the interaction shown in Fig. 3

attempts to align their orientation to enable them to see what is almost hidden, a series of actions that are shaped according to the emerging participation of Jane and Peter. The very ways in which the location and character of the oesteoma is revealed are fashioned in response to the visual and vocal conduct of the trainees and one suspects that even the gestural illustration for Peter arises because of his seeming inability to see the phenomenon in question.

The illustration and instruction emerges within the developing course of the interaction and is dependent upon the surgeon configuring the co-orientation and participation of the trainees. Her successive attempts to reveal the line and osteoma are built though a series of actions that specify a particular alignment and secure an appropriate display of acknowledgement that the objects have indeed been found and seen; they emerge progressively according to the seeming absence of a sequentially appropriate response from the trainees, particularly from Peter. We can begin to see the ways in which the activity's accomplishment emerges through the surgeon's attempts to secure particular forms of participation, differentiating the trainees' alignment, or failure to display alignment, in the course of producing the activity. The activity, and the ability to provide illustration and instruction to the trainees is dependent upon the vocal and visual, and video provides an opportunity to begin to unpack the complex and contingent forms of participation that enable the concerted accomplishment of the interdependent tasks at hand.

\section{CONCLUSIONS}

Video, accompanied by a relevant methodological orientation, provides unprecedented opportunities for those interested in qualitative research into medical practice. It enables the detailed scrutiny of activities and events as they arise within actual, practical situations and provides the opportunity to explore the ways in which health care is accomplished within everyday organisational environments. Unlike more conventional forms of qualitative data, video provides an analytic resource that can be shown and shared with the research community, a community that can include both academic researchers and practitioners, all of whom can bring their expertise to bear upon the quality, insightfulness and rigour of analytic insights and findings. Unlike other forms of recorded data, video also provides the opportunity to capture and reproduce the multimodal qualities of medical practice, not simply the visual, but the ways in which medicine is dependent upon and accomplished through the pervasive use of objects and artefacts, tools and technologies. Video, coupled with a relevant methodological framework, therefore does not simply serve to augment conventional qualitative research in health care, but enables social sciences to reveal a range of phenomena and issues that are of some significance to contemporary medical practice and academic research. These phenomena and issues are exposed not merely by virtue of placing the interactional and contingent at the heart of the analytic agenda, but by recognising that social actions and activities are accomplished through the visual and the material media, as well as the spoken.

Video also provides an opportunity to inform practice in the light of detailed analysis of the interactional accomplishment of health care in everyday working environments. It enables access to the fine, seemingly slight, details of medical work and the ways in which such work is accomplished through, and inextricably embedded within, interaction. In the cases at hand, we can begin to see, for example, how a detailed understanding of the ways in which technologies are deployed and oriented towards within the practicalities of the consultation may not only raise issues concerning how doctors may be helped to ameliorate 
the potentially disruptive effects of computer-based information systems, but may facilitate reflection on the design of such material resources and how they might be (re)configured to ease, if not enhance, the communication between patient and doctor. By contrast, we have much to learn about the ways in which surgeons and other staff in operating theatres, including surgical nurses and anaesthetists, create opportunities to enable observation and learning, and of the interactional resources that are used to temporarily transform how students and others see and participate in the operation. Although field observation, interviews and other methods can provide a range of interesting and insightful information concerning the organisation of health care, it is widely recognised that, in all the various settings within contemporary health care, from consultation to surgery, medical practice is systematically accomplished through the interaction and collaboration of the participants. These interactions and collaborations are multimodal in that they rely upon the interplay of talk, as well as visual and material conduct. Video, accompanied by a relevant methodological framework, provides the resources to enable us to begin to explicate and inform the practicalities of medical work.

Contributors: all authors made substantial contributions to the study conception and design, acquisition of data, and analysis and interpretation of data. All authors contributed to drafting the article or revising it critically for important intellectual content and all authors approved the final version.

Acknowledgements: we would like to thank the patients and staff who generously helped with the research and kindly gave permission for the video-recording of their activities, and Professor David Greatbatch, University of Nottingham and Professor Peter Campion, University of Hull, with whom we undertook a project on the introduction of information technology in general practice and who helped collect the data used in fragment 1. Funding: this project was funded by Rank Xerox Research Laboratories, Economic and Social Research Council and Palcom (IST Programme).

Conflicts of interest: none.

Ethical approval: this research was carried out according to the ethical procedures used by King's College London at the time of data collection in 1998 and 2001, respectively.

\section{REFERENCES}

1 Byrne PS, Long BEL. Doctors Talking to Patients: the Verbal Behaviours of General Practitioners. London: HMSO 1976.
2 Greatbatch D, Heath CC, Campion P, Luff P. How do desk-top computers affect the doctor-patient interaction? Fam Pract 1995;12 (1):32-6.

3 Van der Pasch M, Verhaak PF. Communication in general practice: recognition and treatment of mental illness. Patient Educ Counsel 1998;33:97-112.

4 Pringle M, Robins S, Brown G. Assessing the consultation: methods of observing trainees in general practice. BMJ 1984;288:1659-60.

5 Verhaak PF, Wennink HJ. What does a doctor do with psychosocial problems in primary care. Int J Psychiatry Med 1990;20:151-62.

6 Als AB. The desk-top computer as a magic box: patterns of behaviour connected with the desk-top computer: GPs' and patients' perceptions. Fam Pract 1997;14:17-23.

7 Arborelius E, Osterberg E. How do GPs discuss subjects other than illness? Formulating and evaluating a theoretical model to explain successful and less successful approaches to discussing psychosocial issues. Patient Educ Counsel 1995;25:257-68.

8 West C. Routine Complications: Tasks and Troubles in the Medical Consultation. Bloomington, IN: Indiana University Press 1985;1-288.

9 Peräkylä A. Aids Counselling: Institutional Interaction and Clinical Practice. Cambridge: Cambridge University Press 1995;1-302.

10 Silverman D. Discourses of Counselling: HIV Counselling as Social Interaction. London: Sage 1997;1-244.

11 Maynard D. On clinicians co-implicating recipients' perspective in the delivery of diagnostic news. In: Drew $\mathrm{P}$, Heritage J, eds. Talk at Work: Interaction in Institutional Settings. Cambridge: Cambridge University Press 1992;331-58.

12 Heritage JC, Maynard D, eds. Practising Medicine. Talk and Action in Primary Care Encounters. Cambridge: Cambridge University Press 2006;1-488.

13 Barnes RK. Conversation analysis: a practical resource in the health care setting. Med Educ 2005;39:113-5.

14 Garfinkel H. Studies in Ethnomethodology. Englewood Cliffs, NJ: Prentice Hall 1967;1-288.

15 Sacks H. Lectures in Conversation: Vols I $\mathcal{E}$ II. Oxford: Blackwell 1992;1-580.

16 Koschmann T, LeBaron C, Goodwin C, Feltovich P. Dissecting common ground: examining an instance of reference repair. In: Moore JD, Stenning K, eds. Proceedings of the Twenty-Third Annual Conference of the Cognitive Science Society. Mahwah, NJ: Lawrence Erlbaum Associates 2001;516-21.

17 Sanchez Svensson M. Configuring awareness: work, interaction and collaboration in operating theatres. Unpublished PhD Thesis. University of London 2005.

18 Greatbatch D, Luff P, Heath CC, Campion P. Interpersonal communication and human-computer interaction: an examination of the use of computers in medical consultations. Interacting Computers 1993;5 (2):193-216.

19 Hindmarsh J, Pilnick A. The tacit order of teamwork: collaboration and embodied conduct in anaesthesia. Sociol Q 2002;43 (2):139-64. 
20 Mondada L. Working with video: how surgeons produce video records of their actions. Visual Studies 2003;18 (1):58-73.

21 Heritage J. Garfinkel and Ethnomethodology. Cambridge: Polity Press 1984;1-336.

22 Sacks H, Schegloff E, Jefferson G. A simplest systematics of turn-taking for conversation. Language 1974;50 (4):696-735.

23 Goodwin C. Conversational Interaction: the Interaction Between a Speaker and Hearer. New York: Academic Press 1982;1-195.

24 Heath CC. Body Movement and Speech in Medical Interactions. Cambridge: Cambridge University Press 1986;1288.

25 Heath CC, Luff P. Technology in Action. Cambridge: Cambridge University Press 2000;1-269.

Received 18 January 2005; editorial comments to authors 2 June 2005, 23 November 2005; accepted for publication 1 September 2006

\section{APPENDIX}

\section{Symbols in transcriptions}

The Identity of the speaker is indicated in the margin, sometimes alongside a line number.

This example shows line 1 of a transcript, in which the patient is the speaker.
1 P: I did occasionally go to him:: (.) for: (0.2)

(0.2) A pause timed in tenths of a second

(.) A pause which is noticeable but too short to measure

him:: Elongated utterances - the longer the elongation, the more colons are added to the utterance or section of the utterance

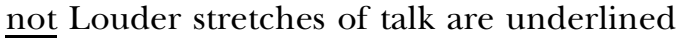

$=$ No discernible interval between adjacent utterances

(is) Words or utterances that are difficult to hear

- A stopping fall in tone, not necessarily the end of a sentence

? Rising inflection, not necessarily a question

Keystrokes on keyboard (in fragment 1, transcript 2)

Overlapping utterances are marked by parallel square brackets.

e.g. Maria: Its very [very tight

Jane: [yeahs 